\title{
MERCADO LABORAL DEL SECTOR CAFETERO EN MARSELLA, RISARALDA
}

Ruth Alejandra Angulo Perea*, Angie Mariana Torres Castaño**, Zulay Daniela Moreno Betancourth***

\section{Resumen}

La presente propuesta de investigación está encaminada al análisis de las causas de la deserción laboral de los recolectores de café en el Eje Cafetero, en Marsella; se delimitó una etapa de 14 años consecutivos para entender cómo esta región ha presentado cambios en su panorama económico, como el aumento del nivel de pobreza, la miseria, la reducción del crecimiento económico, la desigualdad en los ingresos, el incremento en el índice de desarrollo económico, y en la actualidad los caficultores de la región, obtienen una baja rentabilidad por el trabajo realizado. El café es un producto que ha logrado representar no solo a la región; además de esto es un producto que ha tenido mayor importancia a nivel nacional como internacional por su calidad.

* Administración de Empresas, Fundación Universitaria del Área Andina. Correo: rangulo7@estudiantes.areandina.edu.co

* Administración de Empresas, Fundación Universitaria del Área Andina. Correo: atorres73@estudiantes.areandina.edu.co

*** Administración de Empresas, Fundación Universitaria del Área Andina. Correo: 


\section{Introducción}

El Eje Cafetero tiene diversos productos y el más famoso es el café, gracias a su textura y calidad generada por la recolección manual.

Actualmente existen diversos problemas en el sector cafetero, en el ámbito social, económico y cultural en el municipio de Marsella. Este proyecto ayudará no solo a los recolectores y caficultores de Marsella, sino también a todo el sector cafetero de Colombia, ya que identificará una problemática de las regiones cafeteras; determinando las causas que conlleva abandono de esta actividad, se toman medidas para mejorar las condiciones de los trabajadores, con el fin de incrementar la economía y calidad del trabajo de familias colombianas. Por tanto, surge la necesidad de determinar: ¿cuáles son las principales causas de la deserción del mercado laboral campesino para la producción del café en Marsella, Risaralda?

Objetivo general: identificar las causas de la deserción en el mercado laboral del municipio de Marsella, Risaralda.

\section{Objetivos específicos:}

1. Analizar el apoyo que las instituciones gremiales caficultoras ofrecen a los empresarios caficultores.

2. Conocer las políticas implementadas dentro de los planes de desarrollo del municipio de Marsella, Risaralda, encaminadas al sector cafetero.

3. Establecer cuál es la percepción de los empleadores y empleados del sector respecto a la situación cafetera.

\section{Metodología}

La presente investigación se realizará bajo el enfoque mixto con componente cualitativo y cuantitativo.

El enfoque cualitativo se hará mediante entrevistas a los caficultores, gremios y Alcaldía, para identificar su percepción. El componente cuantitativo se realizará por medio de encuestas tanto a los caficultores como recolectores. La encuesta cuenta con variables personales como laborales.

Con una muestra representativa que permita establecer la incidencia de la deserción laboral del municipio de Marsella, ya que es fuerte en la industria cafetera.

\section{Resultados esperados}

Una vez aplicada la recolección de datos, tabularlos y obtenidos los resultados de la problemática, se presentará un informe al gremio y a la Federación Nacional de Cafeteros. Por otra parte, se creará un plan estratégico para mejorar la calidad de vida de todas las personas que realizan esta labor.

\section{Impactos}

Social: mejorar la calidad de vida de la familia cafetera.

Económico: incrementar la productividad mediante esta actividad agrícola, favoreciendo la economía del país.

Ambiental: aprovechamiento de las tierras para el consumo, generando mayor vegetación. 


\section{Referencias}

1. El Insignia. (2017, 8 de noviembre). La importancia del café en Colombia. https://blog.elinsignia.com/2017/11/08/ ea-la-importancia-del-cafe-en-colombia/

2. Muñoz Mora, J. (2010). Ensayos sobre política económica. [Online] Banrep.gov.co. https://www.banrep.gov.co/ sites/default/files/publicaciones/archivos/ espe_063-1.pdf

3. Portafolio.co. (2018, 18 de septiembre). Algunos cafeteros están sembrando coca por los bajos precios del grano. Eltiempo. com. https://www.eltiempo.com/econo$\mathrm{mia} / \mathrm{sectores} /$ algunos-caficultores-siembran-coca-por-bajo-precio-del-grano-269998 